than is yet commonly practised; as this, like the early free incision in diffusive inflammation of the cellular membrane, will prevent the destructive ravages of tissue, as well as the fatal constitutional symptoms which follow the unchecked and protracted course of the disease.

As an illustration of the effects of the dressing here described, I will relate two or three cases.

CASE I. A hout the end of last year, a gentleman, aged 68 , was convalescent after a dangerous attack of bronchitis, which had confined him to bed and to his room for six weeks. At the end of this time, he was regaining the healthy powers of his system; his digestive organs were vigorous; the strength which he had lost was gradually returning; and my attendance upon him had so far declined that he only required a call every third or fourth day, in order to watch his progress. On one of these occasions, in answer to an inquiry how he had been, he said, smilingly, that he was going on very well, but had lost sleep from a troublesome boil; yet, entertaining a belief in the humoral doctrine, that hoils had a healthy indication, he supposed that he must wait patiently until it passed away. Il is countenance, neither on this nor the next visit, denoted any injurious eflects from pain or irritation; but, on calling a third time, I discovered that he was losing the ground which he had gained; his appetite had greatly lessened; and he confessed that he had had little or no sleep for a week, having found no relief in any position from the pain he suffered, although his daughter had very assiduously fomented and poulticed the parts affected. On a closer examination, it was evident that his general powers were decliniur; but, conceiving that his indisposition only arose from a boil, he evinced no anxiety or wish for me to see it. I requested immediately, however, to look at it ; and found a true carbuncle, extending across the loins, and measuring five inches by eight; it formed a broad tumour, with great induration, and was, from interstitial deposit, one and a half or two inches in depth at its centre, decreasing to the circumference. There were two ulcerated points on its surface, showing sloughy cellular membrane within. The nature of the case was clearly apparent; and indeed it might be regarded as one of the later cases of the epidemic which had prevailed for many months in this neighbourhood. The poultices were removed, and the plaister applied according to the plan described; and, though at first it felt, as he said, rather tight and close, his pain was soon relieved; he had a better night than for a week before, being able to turn himself round more readily (he had before spoken of the extreme difficulty of moving, from the severity of pain during the use of poultices). Every succeeding day and night were followed by improvement. It was surprising how little of the cellular membrane sloughed, and how gentle and moderate the suppuration was, considering the formidable character of the tumour. The discharge exuded and escaped regularly through the opening in the plaister, and was absorhed by the pledgets over it; and every renewal of the dressing gave ease a nd comfort it; and every renewal of the dreneral strength were soon regained, and he had not afterwards a single unfavourable sympton. He is at the present time in his usual health, or even better.

In this case, there was no other dressing used but the plaister, reduced in size as the tumour diminished; and the plaister, ref nitrate of silver, to remove a slight excoriation, and to quicken the healing of the two points where the shreds of cellular membrane had escaped. Towards the close of this treatment, a common boil made its appearance within a few inches of the carbuncle; it was treated with a plaister, and its progress at once checked.

CASE II. A few months ago, an old gentleman, aged 75 , always previously of good health and invariable appetite, was seized with two large carbuncles, which he called boils one on the lower end of each scapula. II is pain and suffering were so great for ten days and nights, that, not being able to rest in bed, he spent most of the time in his parlour, partly on a couch, and partly walking bout, but efusing any surgical assistance The poultice system had been persevered in from day to day, without the slightest. abatement of his distress; and he at last consented, at the end of the period abore named, that I should see him. I found his appearance very much altered; his strength and appetite were wholly gone; and he had every symptom of a man fast sinking into death. On examining his back, I found one carbuncle, four inches by four, and another, four inches by six. Each had inflammatory redness, of a low character, on the surface. One showed a point of ulceration, with sloughy cellular membrane within; the other had two points, with a like appearance. I had no expectation of restoring the patient from his prostrate and exhausted condition, as the continuance and severity of pain had produced such an extent of cerebro-spinal lesion as to deprive the digestive organs of all power to take the ingesta requisite for his support. He begged only for relief from his unremitting distress. A plaister was applied to each of the tumours, in the manner described; and, although the vital powers could not be successfully rallied, the effect, upon the diseased parts, of the plaisters, which were renewed every third day, was very surprising, inducing a regular suppuration and detachment of slough, with a manifest increase of comfort and ease to the patient; and his life was prolonged for a fortnight.

CASE III. The third case was that of a gentleman of middle age, who had been poulticing a sloughing boil, about an inch in diameter at the base, which had for several wceks occupied the space between the metacarpal bone of the thumb and fore-finger. He had excellent domestic nursing, but the parts made no progress to healing. He suffered great constitutional irritation, with inflammation of the absorbents of the forearm; and his family bccame anxious about him. The plaister was applied, and gave him immediate relief. A new action was set up; a decp slough, which could not be detached before, was quickly thrown out; he had a daily increase in his comfort; the cavity filled up, and was healed over in a short time. The constitutional condition of this patient was carefully attended to; and, after some weeks, his health was greatly established. Ile had, however, a succession of boils for months afterwards. There was a large one in each axilla; and, though in a most unfavourable situation for treatment, they were pursued, one after the other, by the same method, with equal success, and with little restraint from business.

I think it right to observe, on this occasion, that it has been long a practice with me to use, with a similar object, and from the same mode of reasoning, a like plan of dressing in various classes of tumours, of a subacute or chronic kind, where there is an evident deficiency in the rital actions of the diseased and contiguous parts: and it has appeared to me more successful in many cases than the ordinary treatment by fomentations, poultices, and embrocations. Where there is an unavoidable suppurative tendency, the plaister will accelerate it better than the cataplasm. When the tumour is disposed to point, the cut edges of the plaister, tumour in the former case, should be placed directly over where it is desirable for it to open; and I find it well accomplishes this object. On this subject, however, I may perhaps enlarge at a future opportunity.

Stockport, July 1st, 1833.

\section{THE TREATMENT OF CERTAIN DISEASES IN} REFERENCE TO THEIR PRESENT CHARACTER AND TYPE.

By C. M. DURRANT, M.D., Physician to the East Suffolk Hospital.

(Read before the Suffolk Branch of the Provincial Association, June, 1853.)

"NотнINa, in my opinion, strikes the mind that contemplates the whole and open domain of medicine with greater wonder, than the well known varied and inconsistent character of those diseases which we call epidemic. It is not so much that they reflect and depend upon different condi- 
tions of climate in one and the same year, as that they represent different and dissimilar constitutions of different and dissimilar years." These are the remarks of that close observer of nature, Sydenham ; and it must, I think, be apparent even to the most superficial inquirer into the varying phenomena of disease, that the symptoms which now present themselves to his notice at the bedside are, in reference to their intensity, their progress, and their termination, of a totally changed and modified character, as compared to the distinct and lucid delineations, to which, as a student, his attention has been more especially directed.

That the type of disease generally has, for some years past, been undergoing important modifications, every practical and observant man must be ready to admit. The routine practice of the books, in the treatment of the pyrexiæ, for example, all important as it is as a groundwork for the student's guide, and necessary as it was under the influence of an earlier type of disease, must now be adopted with great caution, and only as the result of that discrimination, which close observation at the bedside can alone confer.

The character of discase at the present day is strictly asthenic. In the most acute attacks, the nervous symptoms will be found, very early in the progress of the case, to assume an important feature in its management. The invalid becomes prostrate very rapidly, and if depressing measures be too vigorously prosecuted at the onset of the treatment, increasing exhaustion will obtain, and the patient will sink, despite the most persevering exhibition of stimulants and tonics.

In the following observations, it is not my intention to enter upon the history of the changes which have taken place in the phenomena of discase during the past twenty or thirty years. An able paper upon this subject, by a member of our Association, Mr. Caleb Williams, printed in the last volume of the Traizsactions, renders it unnecessary. To this instructive essay I would therefore beg to refer, while I confine myself to the consideration of the character of some of the diseases peculiar to the three great cavities, with such general observations upon their treatment as reference to the prevailing type appears to demand.

Commencing with affections of the nervous system, wc shall find that the severe and acute symptoms, with which we have been familiarised by books and lectures, now obtain less frequently, and in a modified form.

Thus the apoplexia gravior of older authors, requiring for its successful treatment large bleedings, repeated again and again, will now no longer, in the majority of cases, demand this heroic and formerly necessary practice. The type of the disease is changed. The greatest discrimination will be requircd. The lancet must be used with caution; or we shall surely find that the vital energy will be irrecoverably depressed, and death, preceded by cold clammy sweats, will too speedily close the scene.

In making these observations, I am far from wishing to deprecate the judicious use of the lancet in the treatment of these affections.

I am only auxious to instil caution :-

1. By bleeding only when alssolutely necessary.

2. By abstracting the smallest quantity of blood commensurate with the severity of the symptoms.

3. I would caution the young practitioner arainst too hastily adopting the heroic practice of the books, without wcll weighing every feature of the case, and at the same time bearing prominently in mind, that the present type of disease generally is of an eminently asthenic character.

Again, in reference to paralysis, so far as my own obscrvations tend to show, we are more familiar now than formerly with this symptom (for it is only a symptom), as a result of cerebral disorganisation-softening. It may be inflammatory, or the contrary; but surely the routine practice of withdrawing a large quantity of blood from the system simply because paralysis obtains, is neither philosophical, nor practically, so far as reported cases in- dicate, is it attended with success. It is in these cases that local depletion to relieve the capillaries, counterirritation, the prolonged exhibition of the bichloride of mercury in sunall doses, and stimulating diuretics, including the tincture of cantharides, often prove of signal service.

Epilepsy, again, in the present day, will noither bear, nor does it require, general blood-letting; and if the theory of Dr. Marshall Hall be correct, the laryngismus will not be removed by large depletions.

Not less apparent is the altered type of disease, as evidenced in the cerebral affections of infancy.

Notwithstanding the injunctions laid down by authors, in reference to opening the jugular vein, and the repeated application of leeches, in some of these affections, I must admit that the propriety of doing so is contrary to the experience which my own observation has afforded. Indeed, cases have occurred, in which the abstraction of blood, even by a single leech, has, by further prostrating the already depressed vital power, induced death from irremediable exhaustion.

It will be unnecessary for me farther to advert to the great similarity which obtains, in many cases, between the symptoms arising from the two extremes of cerebral disturbance, as seen in children, viz., the hyperæmic and anemic conditions of the brain. That the latter exists in the present day more frequently than is imagined cannot, I think, be denied; and if, under these circumstances, eren a small quantity of blood be withdrawn from the system, a fatal termination of an hydrencephaloid character may very probably result.

It is in these cases that a woll regulated diet, with strict and deily personal inspection of the alvine evacuations, coupled with the exhibition of the salts of iron, and above all, cod-liver oil, will often, even under apparently hopeless circumstances, be attended by the happiest results.

It is not, however, only in the anemic condition of the brain above referred to, that we are to exercise such caution in the use of depletory measures, but also in those cases of a more acute character, which formerly required and were benefited by a correspondingly active treatinent.

Passing from the head to the chest, we cannot fail to notice the result of the asthenic constitution, as evidenced more particularly by pleurisy and pneumonia. I need only appeal to the experience of those who have been in practice some years, to be assurcd that they are now called upon to use the lancet much less frefuently than formerly.

The observations of all, if carefully made, will equally prove that the symptoms of these very acute diseases, are now frefuently far from bcing of that sthenic decided character, which formerly required such vigorous and active depletory treatwent.

Again and again, have I witnessed the difficulty which has been experienced in restoring the powers of the system during the convalescence from pneumonia, previously reduced by only a single bleeding.

The character of the symptoms is changed, and the tendency of pneumonia now is, unless the vital tone be sufficiently maintained, to assume a chronic form; the lung bccoming more or less condensed by conversion into a dirty greyish mass of cacoplastic deposit.

Another termination of the low form of pneumonic inflammation, by no means unfre iuent under the influence of the present type of disease, is gangreuous abscess; and although the prognosis in reference to recovery under these circumstances is, on the whole, favourable, still the necessity of refraining from the indiscriminate use of the lancet cannot be too strongly urged, in order to avoid the inducement, by lowering measures, of this formidable complication. Inflammation of the serous membrane, whether of the chest or abdomen, is equally prone to the depressing influence of the prevailing type. Acute pleurisy and peritonitis are now, numerically speaking, of rare occurrence when compared to the great frequency of these affections under a more asthenic form.

Instead of the severe stabbing pain, and intense fever, with the progressive well known symptoms, formerly so 
constant an accompaniment, we are now frequently called upon to combat an amount of disease, the existence of wich, from the negative character of the direct symptoms, has been almost unsuspected by the patient himself. It must have occurred to all to be surprised at the amount of thoracic, as well as abdominal disease, in connexion with inflammation of the serous membranes, which has been found to obtain, while the patieut, farther than feeling weak and somewhat out of health, has scarcely been compelled to forego his usual occupation.

In these cases, if a too lowering treatment be adopted, the necessary reparative powers will incvitably be interfered with; and a cacoplastic, or even tuberculous deposit upon the membrane, with a dirty, shreddy collection of sero-purulent fluids within its cavity, will be the result of the too active remedial interference.

Not only to the diseases to which I have thus in the foregoing observations very cursorily alluded, but also to fevers, pucrperal affections, and the whole extensive range included within the limits of toxamic influence, will similar remarks apply.

In conclusion, I may state, that in troubling you with these observations, it has not been under the impression that I could advance anything novel, but because I have felt, and daily experience convinces me of the fact, that the amount of influence which is exerted upon disense by its prevailing type is not sufficiently regarded. I have been anxious only to instil caution, and to insure reflection, prior to using as a routine necessity the powerfully depressing measures which we possess, and by the indiscriminate adoption of which we expose ourselves to the impertinent inuendos and insinuations of the followers of the leading quackery of the day.

The judicious abstraction of blood by the lancet will unquestionably every now and then be necessary ; but he who will allow himself to regard its use as an exceptional, rather than as a necessary part of the treatment of the majority of diseases as they at present obtain, will prove, I can but think, the most successful practitioner. The tendency of inflammatory affections, particularly of the lung, while it exalts the sensibility of the diseased portion, undoubtedly depresses the system generally. An active eliminative treatment, powerfully operating through the three great channcls of the skin, the bowels, and the kidneys, may, in the majority of cases, be beneficially substituted for general bloodletting.

These measures, by avoiding the unduly lowering the powers of life, and by not interfering with the process of repair, so necessary to the cure, will tend to insure a safe and comparatively short convalescence, free from that depressing debility to which, in the strumous subject, is so frequently to be traced the first commencement of tuberculous cachexia.

Ipswich, July 18:53.

\section{CASE OF RECOVERY AFTER COMPOUND FRACTURE OF THE FRONTAL BONE, AND LOSS OF CEREBRAL SUBSTANCE.}

\section{By GEORGE MALLETT, Fisq.}

TuE following case of severe cerebral injury is, I think, important and intcresting. It proves very decidedly that Vil desperandum ought to be the motto of a surgeon; and it also exhibits in a remarkable manner the wonderful power of nature in repairing injuries that are apparently mortal.

CAsE. R. Booth, aged 60, a stonemason, was struck on the forchead by the handle of a windlass in rapid motion. He was taken up by his fellow labourers quite insensible, and conveyed to his house, about a quarter of a mile from the spot.

The medical gentleman residing in the neighbourhood soon saw him; and considering the case to be utterly hope- less, and that life could not continue many hours, he came to the conclusion that nothing could or ought to be done.

The accident occurred in the afternoon; and on the following morning I was requested to visit the man, as he was still alive.

Upon examination, the frontal bone was found to have received a compound fracture and to be much shattered. The entire breadth of the bone, and from one inch to an inch and a half of its height were driven into the brain. A very considerable quantity of the cerebral matter was adherent to the adjoining parts.*

The man was quite insensible; the breathing was slow and almost stertorous; the pulse slow and full.

I had formerly seen some desperate cases of cerebral injury, which recovered: an account of which was published in the seventh volume of our Transactions. I therefore at once resolved to remove the fractured pieces of bone and give him a chance.

Mr. B., the medical man who had seen the case on the preceding evening, was sent for; but he not being at home, 1 , with the assistance of a medical friend, proceeded to remove the shattered fragments of the frontal bone, some of which were found deeply imbedded in the substance of the brain. Twelve pieces of various sizes were removed, and still the man remained quite insensible to our operations; but on the extraction of the thirteenth, and, as it proved, the last, which was a larger piece and more deeply imbedded than the others, he started up in bed and uttered -no doubt from his accustomed habit, and quite unconscious of what had been going on-an oath. Water dressing was applied, and the head was directed to be kept cold by the constant application of that fluid to the scalp.

I saw him on the following morning, and found him quite sensible, and exhibiting no unfarourable symptoms. I left him in charge of the neighbouring surgeon, requesting that his bowels should, if necessary, be occasionally relieved by a little castor oil ; and we agreed that if any unfavourable symptoms should arise, I should be immediately informed. The only intelligence I had was, that he was gradually advancing towards a restoration to health; and after a few weeks I heard no more of the case, and therefore concluded that all was well.

About three months after the accident, I was greatly surprised and pleased to see the man enter my surgery, having walked from his own home, the distance being from three to four miles. The wound was completely healed by granulations, but had left a most frightful deficiency of bone. The pulsations of the brain were seen immediately under the newly formed skin. His intellect, as far as I could judge, was unimpaired; and the muscular power not at all paralysed. In fact, I may say, as he did, that he was quite well. I never saw him afterwards : but I was quite convinced, and endeavoured to convince him, how precarious his existence must be without the greatest care, from the very delicate and insufficient protection which the anterior portion of the brain possessed, being deprived of so large a portion of the frontal bone, no reproduction of which was: to be expected.

$$
\text { Bolton, July 2nd, } 1353 .
$$

[This interesting case is another illustration of the impropricty of forming an absolutely unfavourable prognosis in certain cases of compound fracture of the skull, even when accompanied by considerable loss of cerebral substance. Recoveries are not at all uncommon, when the bone which is broken is the frontal, and the portion of brain lost belongs to the same region. Confirmation of this remark will be found at p. 375 of our Periscopic Review for 29th April.-EdrTor.]

- The quantity of brain lost could not be accurately estimated, but it was not thought to be less than from one to two tablespoonfuls. 